\title{
TECNOLOGIA, ESCOLA, PROFESSOR
}

No século XV as caravelas portuguesas, depois de muitos dias e noites, aportaram aqui. Pero Vaz de Caminha, o "repórter" de confiança da Coroa portuguesa, mandou a notícia. Ele escreveu:

"Esta terra, Senhor, (...) em tal maneira é graciosa que, querendo-a aproveitar, dar-se-á nela tudo; por causa das águas que tem."

Essa notícia chegou imediatamente a Portugal. Meses depois. Esse era o tempo do "imediatamente".

Hoje, assistimos a guerras, a assassinatos, a festas, muitas vezes no mesmo momento em que ocorrem. É o "imediatamente" de hoje. A diferença de tempo entre a divulgação dessas notícias se deve ao avanço da tecnologia: é ela que reduz o tempo e encurta distâncias. Os pontos mais distantes do planeta são trazidos para a sala de nossa casa. Este é o novo mundo.

Hoje, provavelmente, Caminha mandaria um fax para a Coroa e a correspondência secreta iria por avião.

Os avanços tecnológicos compõem a nova realidade. A cada conquista, há uma reconfiguração do anteriormente conquistado. Nenhum deles desaparece: fotografia, cinema, televisão, computador.

Essas mudanças estão aí, não há como escapar. Com um telefone e um computador temos acesso ao mundo em segundos. Dessa vez, há os que dizem que a escola acabou. O professor foi substituído pelo computador, pelo vídeo e pela televisão. Será?

Esse contato diário com tantas outras culturas, resultado das novas tecnologias, implica uma rápida e permanente atualização da nossa cultura: instaura-se uma reconfiguração das instituições e uma discussão de valores. Permite, desse modo, que consolidemos nossos valores, ratificando-os ou reformulando-os. Permanecerão na nossa cultura aqueles traços que todos decidir-

\section{A AUTORA}

Maria Aparecida Baccega

Doutora em Letras e Ciências da Comunicação. Professora Associada da Escola de Comunicações e Artes da USP. Especialista em Linguagem Verbal nos Meios de Comunicação. Coordenadora do Curso "Gestão de Processos Comunicacionais". 
mos como marcas da diferença, as quais nos distinguirão no conjunto das culturas, na inter-relação com elas. São os traços que mostram nosso jeito de ser e de viver e fazem que todos nos sintamos participantes do mesmo universo, da mesma nação. E, a partir desses traços, seremos identificados e respeitados.

Assim vai se dando, com a rapidez que a tecnologia permite, o processo de construção/reconstrução de identidades, inseridas todas na internacionalização do mundo, ao mesmo tempo em que se reforçam, pelas marcas da diferença, as culturas locais e regionais.

Essa mudança no perfil da sociedade atinge a escola, exigindo que ela se dedique, cada vez mais, a seu objetivo maior: a formação de cidadãos críticos. Logo, essas mudanças consolidam a instituição escolar e sobrelevam o papel do professor.

As ofertas de produtos que podemos ler, ouvir e ver aumentam a cada dia. Entre tantos, podemos citar a TV a cabo, que nos permite ter acesso a programas de várias partes do mundo, no momento em que estão acontecendo. Mas o nosso dia continua a ter 24 horas.

É preciso, portanto, que se saiba, primeiro, escolher o que queremos ver, ouvir e ler; segundo, que saibamos "ler" esses produtos, inter-relacionando-os entre si e relacionando-os com o que acontece ao nosso redor; terceiro, que essa inter-relação seja resultado da consolidação de objetivos que reflitam a nossa cultura e a construção de um mundo mais humano.

Para que isso ocorra, é fundamental garantir o espaço de reflexão. E o espaço privilegiado de reflexão é sempre, e continuará sendo, a escola. E a coordenação do processo estará sempre nas mãos do professor.

Sabemos que a tecnologia está na escola. Não exatamente na forma de aparelhos sofisticados (ainda são tão poucas as que os possuem, disponíveis para todos) mas sim na cultura dos alunos que nela estão. Eles são resultado desse mundo pleno de tecnologias, dessa nova cultura, independentemente do nível sócio-econômico a que pertencem. Por isso, no campo da educação, o desafio maior tem sido a busca da incorporação dessa tecnologia na dimensão sócio-cultural.

Nessa reconfiguração e redimensionamento da escola, um dos eixos é ensinar o aluno a trabalhar a informação, dando-lhe condições de incorporála a partir do conjunto de idéias, valores e objetivos de sua cultura, utilizando-a para colaborar na solução dos problemas de sua realidade.

É necessário, sem dúvida, que os aparelhos tecnológicos estejam à disposição das escolas. Porém, o que estamos querendo mostrar é que, mais importante que essa etapa, é fundamental que sejam dadas ao professor condições para ser o grande condutor nos caminhos desse mundo de realidades virtuais e de realidades vividas e construídas.

Só a escola poderá formar cidadãos que usem a tecnologia para diminuir a distância entre o homem-cidadão e o homem desrespeitado na sua condição humana. 
O uso do computador, por exemplo, tem se revelado de grande valia no ensino. Porém, se o uso do computador ocorrer apenas na perspectiva de instrução, seu valor ficará drasticamente reduzido. A educação continuará a ter como base a reprodução do conhecimento e o computador servirá apenas para colocar à disposição do aluno, descritivamente, uma gama maior dos conhecimentos que a humanidade já acumulou.

Agora, imaginemos: computador ligado, acessamos uma outra pessoa, com a qual estamos mantendo conversação. Como faremos isso? Certamente, escrevendo. Ou seja: o avanço da tecnologia, o uso intensivo do computador faz voltar com muita força também a necessidade da escrita. Logo, faz voltar, com muita força, o papel primeiro da escola: ensinar a ler e escrever. $\mathrm{E}$ fazê-lo com conteúdo crítico.

O computador, o vídeo ou os outros aparelhos têm que ser vistos como uma ferramenta a mais no processo de educação. E uma ferramenta que deverá ser usada pelo professor a partir de seus objetivos, a partir do planejamento que ele elaborou, objetivando o acesso crítico ao conhecimento. Por isso, podemos afirmar, sem cometer exagero: o papel primeiro da escola, de ensinar com criticidade, é retomado de maneira definitiva nesses novos tempos de tecnologia. À escola compete educar, ou seja, fazer com que o aluno aprenda a aprender.

A tecnologia obriga a escola a ser o que sempre objetivou ser: crítica, fazendo do aluno não um vaso recipiente de conhecimentos prontos - passivo, portanto -, mas um ser ativo, um sujeito da História. Com a ajuda de mais ferramentas.

\section{ARTIGOS NACIONAIS}

Alfredo Bosi, em Educação: as pessoas e as coisas, expõe com clareza a situação de inferioridade em que se encontra o professor. Trabalhando com dados oficiais, o autor mostra que a faixa salarial do professor vai de $\mathrm{R} \$ 0,50$ a $\mathrm{R} \$ 2,00$ (nos estados mais aquinhoados) por aula. Esse é o profissional que conduzirá os cidadãos brasileiros nos caminhos das realidades virtuais ou não. Será isso possível? Para o autor, o que temos presenciado é o "primado das coisas sobre as pessoas. Computadores aos milhares sem professores prezados e estimulados são sucata virtual".

O mesmo tema é abordado por outro artigo: Multimídia na educação, de Dora Incontri. Segundo a autora, "a educação atual não atende a dois princípios básicos: ela não forma integralmente o homem, ao invés, fragmenta conhecimentos que ficam sem relação entre si, e desenvolve potencialidades parciais, apelando mais à memória que ao raciocínio, mais à passividade que à iniciativa, negligenciando a criatividade, a estética e a ética". A partir dessa constatação, a autora discute a importância do uso das tecnologias, sobretudo o $C D$-Rom, mostrando a importância do papel do profes- 
sor para que essas tecnologias "não se transformem em mais um reduto de lixo cultural e de exploração capitalista desenfreada".

A dimensão social do meio ambiente, artigo de Célia P. de Carvalho, Heloísa Bettiol, Marco A. Barbieri e Marisa Ramos Barbieri ajuda a colocar as coisas no lugar. Será que devemos apenas chorar a morte das baleias ou será que o homem continua a ser o centro da questão do meio ambiente? E, afinal, quais deveriam ser as condições básicas para o desenvolvimento de uma educação ambiental adequada? Qual o papel de professores e de profissionais da saúde neste campo tão divulgado e tão pouco discutido? Vale a pena ler, posicionar-se e contactar o Laboratório de Ensino de Ciências.

Também Antônio Luís Cagnim coloca as coisas no lugar. Só que, desta vez, o tema é a história das histórias em quadrinhos. No artigo Yellow Kid, o moleque que não era amarelo, o centro da discussão é o "nascimento" de Yellow Kid, e o fato de essa data ser comemorada como o nascimento das histórias em quadrinhos. Segundo o autor, muitas histórias já haviam sido contadas em imagens "muito antes que aquele moleque balbuciasse os primeiros balões de suas gags, no jargão das favelas de Nova Iorque". Entre desenhistas que o antecederam, o autor lembra o nosso Ângelo Agostini.

A violência tomou conta da mídia. De repente, descobriram que se tratava de um filão muito rico para dar destaque aos programas e aumentar a audiência. Elisabeth Rondelli, em Dez observações sobre mídia e violência enfrenta o assunto. Trata-se de uma valiosa colaboração para professores, pais e educadores em geral. Como diz a autora, "os chamados crimes contra a pessoa - um roubo de casa, um assalto na rua, um homicídio - são mais visíveis, detectáveis e passíveis de serem transformados em imagens dos noticiários do que estes outros crimes de corrupção, menos sujeitos a serem apreendidos por qualquer imagem".

Será que essa violência influencia os ouvintes, leitores e telespectadores? Este tema está também tratado no artigo de José Martinez de Toda y Terrero.

\section{ARTIGOS INTERNACIONAIS}

Tanto $O$ impacto moral e social dos meios de comunicação, artigo de José M. de Toda y Terrero, quanto A televisão e as crianças, artigo de W. Cordelian, Juan Antonio Gaitan e Guillermo Orozco Gomez discutem a influência dos meios, sobretudo a televisão, sobre os receptores. No primeiro, a violência é a grande questão e desencadeia a busca de respostas. Apresentando e discutindo criticamente grande número de pesquisas sobre o tema, os artigos nos permitem avançar bastante no conhecimento da problemática. 


\section{ENTREVISTA}

O número 7 tem muito motivo para comemoração: ele traz a entrevista de Janio de Freitas e inaugura o terceiro ano consecutivo da revista Comunicação \& Educação. O jornalista, parâmetro de dignidade profissional comprovada ao longo dos anos de trabalho, fala a Roseli Fígaro de sua atuação nos diferentes períodos histórico-políticos do Brasil, não poupando análises críticas, como é sua característica. Começamos bem esta etapa.

\section{CRÍTICA}

Ninguém melhor que Renata Pallottini, pela sua condição de saber fazer e saber refletir sobre o que f̣az, para escrever sobre a questão que está na pauta das conversas das pessoas e das decisões das emissoras de televisão: telenovela ou minissérie? Mas qual é, afinal, a diferença entre as duas manifestações do gênero? É o que a autora nos conta em seu artigo Minissérie ou telenovela.

O Quatrilho, filme brasileiro, concorreu ao Oscar. Não ganhou. Mas já foi visto por milhões de pessoas. Por que, "de repente", o cinema nacional está voltando? Qual a importância de ter sido indicado para o Oscar? Quem trata disso é Marília Franco, professora e pesquisadora de cinema, com vasto trabalho nas questões referentes a cinema e educação. Em $O$ sentido do Oscar, ela nos dá importante contribuição para que possamos discutir essas questões em sala de aula.

\section{DEPOIMENTO}

Rosicler Martins Rodrigues nos conta, em Paradidático e educação: uma conversa informal, porque optou por escrever livros paradidáticos. Mostra qual o objetivo desses livros, a importância que eles conquistaram no processo educacional e a vasta pesquisa que ela precisa fazer cada vez que se dispõe a produzir uma obra. Com ela, penetramos o mundo da construção do conhecimento com que o livro paradidático colabora.

Tão saboroso quanto uma charge é o artigo Humor da charge política no jornal, do chargista Gilberto Maringoni. Ele situa historicamente a charge (como Cagnim, lembra também Ângelo Agostini) e discute a inserção do chargista na imprensa.

\section{EXPERIÊNCIA}

Quem conta a experiência é Marli Siqueira Leite, professora de primeiro e segundo graus. Vivências poéticas mostra, com depoimentos e trabalhos dos alunos, como tornar a poesia presente na sala de aula e na vida dos alu- 
nos. O texto vai reconstruindo, passo a passo, a experiência. Pode ser uma boa idéia realizá-la com seus alunos.

\section{POESIA}

O vento no canavial, de João Cabral de Melo Neto, é a poesia escolhida.

\section{SERVIÇOS}

Lígia Trigo, diretora da Rádio USP, é a autora do artigo Rádio USP, a FM que toca todas as línguas. O texto aponta os objetivos da rádio e mostra como esses objetivos vêm sendo alcançados, através de uma programação diversificada.

Outro seviço que a revista apresenta é o Museu de Anatomia Veterinária. Em artigo de Arani Nanci B. Mariana, ficamos sabendo o que o Museu oferece e como fazer para ter acesso a ele.

\section{BOLETIM BIBLIOGRÁFICO}

A Videografia, de Ismar de Oliveira Soares e Maria Ignês Carlos Magno, discute o período JK. Continuam a Bibliografia especializada na área de Comunicação e Educação, de Ismar de O. Soares, e a Bibliografia especializada sobre a telenovela brasileira, de Anamaria Fadul. Esperamos que continuem merecendo os elogios que essa seção vem recebendo. 